\title{
PERANAN SISTEM INFORMASI DENGAN ONLINE TRADING TERHADAP PERTUMBUHAN PASAR MODAL DI INDONESIA
}

\author{
Riswan Efendi Tarigan \\ MTI Department, Graduate Program, Binus University \\ Jl. Kebon Jeruk Raya No. 27, Kebon Jeruk, Jakarta, 11530 \\ re.tarigan@gmail.com
}

\begin{abstract}
Capital Markets is part of the financial market, which is related to the supply and demand of the need for long-term funding. Capital Markets was formed and developed with aims to support the implementation of national development in order to improve the distribution, growth, and stability of the national economy towards the improvement of society welfare. However, so far the capital market in Indonesia is still around $0.5 \%$ of the total population which is too small compared to capital markets in other advanced countries. One solution for increasing community involvement in the capital market, despite educating in smart and sustainable way, is developing and implementing efficient information systems, so that made it easier for market participants to undertake investment activities. This paper examines how and to what extent the role of information system enhances the capital market in Indonesia, which aims to plan the subsequent strategic step so that the development of Indonesia's capital market is able to compete in global market.
\end{abstract}

Keywords: financial market, capital market, information system

\begin{abstract}
ABSTRAK
Pasar Modal merupakan bagian dari pasar finansial, yang terkait dengan supply dan demand akan kebutuhan dana dalam jangka panjang. Pasar Modal dibentuk dan dikembangkan dengan tujuan untuk menunjang pelaksanaan pembangunan nasional dalam rangka meningkatkan pemerataan, pertumbuhan, dan stabilitas ekonomi nasional kearah peningkatan kesejahteraan masyarakat secara menyeluruh. Namun, sejauh ini pelaku pasar modal di Indonesia masih sekitar 0,5\% dari total penduduk, sangat jauh dibandingkan pelaku pasar modal di negara lain yang lebih maju. Salah satu solusi untuk meningkatkan keterlibatan masyarakat di pasar modal, selain melakukan edukasi secara cerdas dan berkesinambungan, adalah pengembangan dan penerapan sistem informasi yang efisien, sehingga memberi kemudahan bagi pelaku pasar untuk melakukan aktivitas investasi. Tulisan ini mengkaji bagaimana dan sejauh mana peranan sistem informasi untuk meningkatkan pelaku pasar modal di Indonesia yang bertujuan untuk merencanakan langkah strategis selanjutnya agar perkembangan pasar modal Indonesia mampu bersaing dengan dalam ranah global.
\end{abstract}

Kata kunci: pasar finansial, pasar modal, sistem informasi 


\section{PENDAHULUAN}

Aktivitas pasar modal di Indonesia terlihat mulai meningkat sejak tahun 1988, ditandai dengan peluncuran paket deregulasi dibidang perbankan dan pasar modal.

Sejak saat ini, jumlah pelaku pasar modal (baik emiten juga investor) secara bertahap bertumbuh terutama setelah pemerintah mengeluarkan Paket Desember 88 (PAKDES 88) yang memberikan kemudahan perusahaan untuk go public dan sejumlah kebijakan lain yang positif bagi perkembangan pasar modal. Pelaku pasar modal semakin bertumbuh sejak diaplikasikannya sistem perdagangan jarak jauh (remote trading) di tahun 2002. Momen tersebut merupakan cikal bakal peningkatan pertumbuhan pelaku pasar modal secara berkesinambungan. Hal ini sekaligus berdampak positif bagi pertumbuhan perekonomian secara nasional.

Dalam industri keuangan, khususnya pasar modal, keberadaan dan kelengkapan informasi merupakan hal yang sangat penting karena menjadi dasar dalam pengambilan keputusan investasi. Investor akan memiliki kesempatan yang sama, luas dan rasional dalam menentukan pilihan investasi, bila didukung dengan ketersediaan informasi yang baik, lengkap, dan benar. Hal ini juga merupakan syarat terbentuknya pasar yang lebih efisien.

Perkembangan dan pemanfaatan teknologi informasi secara efektif, dengan ketersediaan berbagai fitur berita dan informasi keuangan, memudahkan pelaku pasar tanpa hambatan waktu dan batasan geografis. Sejalan dengan meningkatnya peranan Internet, semakin memudahkan dalam hal akses (accessability), biaya yang relatif lebih murah (cheaper), serta kecepatan untuk memperbarui informasi (updating).

Studi ini bertujuan sebagai kajian awal sekaligus memetakan sejauh mana peran serta teknologi dan sistem informasi dalam perkembangan pasar modal di Indonesia. Dengan demikian, akan terlihat seberapa besar manfaat teknologi dan sistem informasi untuk menyebarkan informasi yang relevan bagi para pelaku yang berkepentingan terhadap pasar modal. Selanjutnya, lewat kajiankajian multi-disiplin yang lebih komprehensif akan dikembangkan model-model dukungan yang bermanfaat bagi pertumbuhan dan perkembangan pasar modal di Indonesia.

\section{METODE}

Kajian ini bersifat studi kepustakaan (library research). Metode studi yang dilakukan dalam kajian ini, meliputi: (1) studi pustaka - data data yang diperoleh dengan jalan membaca dan mengutip berbagai literatur yang mendukung tulisan ini. Di samping itu, data juga diperoleh dari pelbagai publikasi media massa, jurnal pasar modal, serta publikasi lain yang memuat informasi yang relevan dengan kajian ini; (2) riset melalui internet dengan mengunjungi website bursa efek Indonesia dan lembaga pengawas pasar modal. Hal ini untuk mencari peraturan dan regulasi terkait penerapan dan pemanfaatan teknologi dan sistem informasi di pasar modal; (3) telaah riset-riset sebelumnya - hal ini dilakukan untuk menelaah riset-riset yang telah dilakukan terkait topik-topik yang mengkaji pemanfaatan teknologi dan sistem informasi untuk mendukung pertumbuhan pelaku pasar modal di Indonesia. Berikut adalah dasar teori terkait investasi, informasi, dan sistem informasi.

\section{Teori Investasi}

Investasi adalah penempatan sejumlah dana dengan harapan dapat memelihara, meningkatkan nilai, atau memberikan imbal hasil (capital gain) yang positif (Sutha, 2000). Webster (1999) 
mengatakan investasi adalah penanaman modal uang dengan harapan mendapat hasil dan nilai tambah (value added). Menurut Lypsey et al. (1997), investasi adalah pengeluaran barang yang tidak dikonsumsi saat ini dimana berdasarkan periode waktunya, investasi terbagi menjadi tiga, yaitu: investasi jangka pendek, investasi jangka menengah, dan investasi jangka panjang. Investasi merupakan komitmen sejumlah dana pada suatu periode untuk mendapatkan pendapatan yang diharapkan dimasa yang akan datang sebagai unit kompensasi. Unit yang diinvestasikan meliputi waktu yang digunakan, tingkat inflasi yang diharapkan dan ketidakpastian masa mendatang.

\section{Pasar Modal dan Bursa Efek}

Pasar modal (capital market) adalah suatu bidang usaha perdagangan surat-surat berharga seperti saham, sertifikat saham dan obligasi (efek-efek). Motif utama dari pasar modal tersebut adalah masalah kebutuhan modal bagi perusahaan yang ingin lebih memajukan usahanya dengan menjual sahamnya kepada pemilik dana, investor, baik perorangan maupun lembaga usaha.

Instrumen keuangan yang diperdagangkan di pasar modal merupakan instrumen jangka panjang (jangka waktu lebih dari satu tahun) seperti saham, obligasi, waran, right, reksa dana, dan berbagai instrumen derivatif seperti option, futures, dan lain-lain.

Undang-Undang Pasar Modal No. 8 tahun 1995 tentang Pasar Modal mendefinisikan pasar modal sebagai "kegiatan yang bersangkutan dengan Penawaran Umum dan perdagangan Efek, Perusahaan Publik yang berkaitan dengan Efek yang diterbitkannya, serta lembaga dan profesi yang berkaitan dengan Efek”(Bappepam Online, 2005).

Wai dan Patrick (1984) dalam Departemen Penerangan dengan sebuah paper IMF yang berjudul "Such or Bond Investment and Capital Markets on Less Developed Countries" menjelaskan beberapa pengertian pasar modal, yaitu: (1) definisi luas: pasar modal ialah kebutuhan sistem keuangan yang terorganisir, termasuk bank-bank komersil dan semua perantara di bidang keuangan, serta surat-surat kertas berharga atau klaim, jangka panjang dan pendek, primer dan yang tidak langsung; (2) definisi dalam arti menengah: pasar modal ialah semua pasar yang terorganisir dan lembaga-lembaga yang memperdagangkan warkat-warkat kredit (biasanya berjangka lebih dari 1 tahun) termasuk saham-saham, obligasi-obligasi, pinjaman berjangka hipotik dan tabungan serta deposito berjangka; (3) definisi dalam arti sempit: pasar modal adalah tempat pasar terorganisir yang memperdagangkan saham-saham dan obligasi-obligasi dengan memakai jasa makelar, komisioner, dan para underwriter.

Secara umum pengertian pasar modal ialah pasar abstrak yang juga sekaligus konkrit dimana yang diperjualbelikan adalah dana-dana jangka panjang (abstrak) yakni, dana-dana yang berjangka lebih dari satu tahun, dalam bentuk surat-surat berharga di bursa efek (konkrit).

\section{Teori Informasi}

Raymond Mc.leod (2001) mendefinisikan informasi sebagai data yang telah diolah menjadi bentuk yang memiliki arti bagi si penerima dan bermanfaat bagi pengambilan keputusan saat ini atau mendatang. Pengertian Informasi Menurut Bodnar dan Hopwood (2000) adalah data yang diolah sehingga dapat dijadikan dasar untuk mengambil keputusan yang tepat.

\section{Sistem Informasi}

O’Brien (2005) menyatakan bahwa sistem informasi adalah suatu kombinasi teratur apapun dari people (orang), hardware (perangkat keras), software (piranti lunak), computer networks dan data 
communications (jaringan komunikasi), dan database (basis data) yang mengumpulkan, mengubah dan menyebarkan informasi di dalam suatu bentuk organisasi.

Sementara menurut Gordon B. Davis (1991), sistem informasi adalah suatu sistem yang menerima masukan data dan instruksi, mengolah data tersebut sesuai dengan instruksi dan mengeluarkan hasilnya.

\section{HASIL DAN PEMBAHASAN}

Berdasarkan kinerja pasar modal Indonesia diakhir penutupan perdagangan, Kamis 27 Desember 2012, Indeks Harga Saham Gabungan (IHSG) ditutup pada posisi 4.821,86 atau menguat 12,03\% dibandingkan penutupan perdagangan akhir tahun 2011 (Gambar 1). Dengan kinerja tersebut, posisi IHSG Indonesia menduduki peringkat ke-8 tertinggi di dunia. Hal tersebut, ditopang oleh regulasi pemerintah yang pro terhadap pasar modal, juga tingkat kepercayaan masyarakat terhadap emiten di Indonesia, dan dukungan infrastruktur yang memadai.

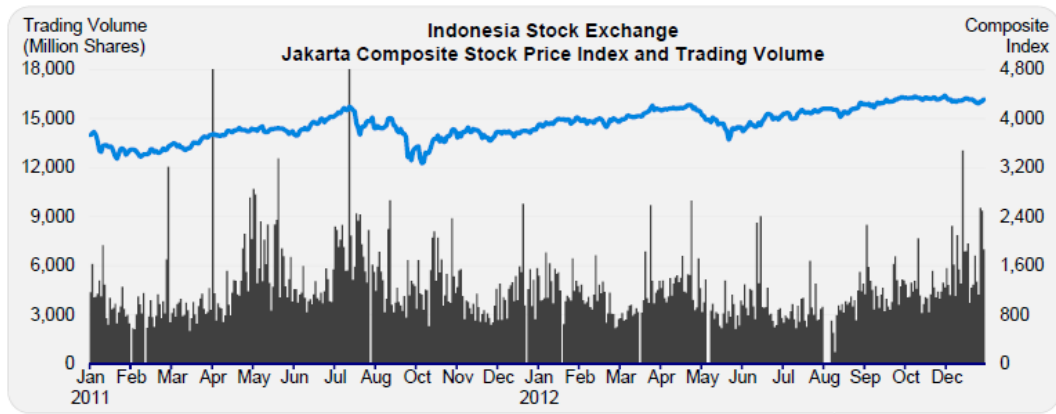

Gambar 1 Kinerja IHSG pasar modal Indonesia 2011-2012 (Indonesia Stock Exchange, 2013)

Terkait dengan hasil riset Herni Widanarti (2002), agar pasar modal Indonesia efektif dalam kinerja membutuhkan tiga unsur pendukung yaitu: infrastruktur yang memadai, kerangka hukum yang kokok (regulasi pemerintah), dan sikap profesional dari para pelaku pasar modal (menjalankan etika bisnis dengan baik dan benar).

Pimpinan Bapepam-LK (saat ini menjadi Otoritas Jasa Keuangan (OJK)) menyebutkan secara statistik, jumlah investor di pasar modal Indonesia baru mencapai 363.094 investor. Sekitar 0,2\% dari jumlah penduduk Indonesia (Sriwijaya Post, 2012). Persentase ini jauh lebih kecil bila dibandingkan dengan negara-negara yang pasar modalnya lebih berkembang. Singapura sudah mencapai $30 \%$ dari jumlah penduduk, dan Malaysia mencapai 20\% dari jumlah penduduk. Selain investor, jumlah emiten di pasar modal Indonesia juga tergolong masih rendah. Saat ini jumlah emiten baru mencapai 443 emiten. Angka itu masih lebih kecil dari jumlah emiten di Hong Kong, Singapura, dan Malaysia yang besarnya secara berturut-turut adalah 1.518, 789, dan 935 emiten.

Namun, dari jumlah investor yang ada saat ini, telah ada peningkatan $45 \%$ jumlah investor lokal selama tahun 2012. Meskipun ada peningkatkan, bila dibandingkan jumlah investor asing (70\%), investor domestik hanya 30\%. Hal ini cukup berisiko terhadap pelarian modal (capital outflow).

Berdasarkan Tabel 1 dan Gambar 2, bila dibandingkan dengan negara-negara lain, pasar modal Indonesia bertumbuh (YoY) diatas Korea, Malaysia, Singapura, Hongkong, China, India, dan 
Amerika Serikat. Dengan demikian, dapat dikatakan bahwa pertumbuhan pasar modal Indonesia relatif lebih baik dibandingkan negara-negara maju lainnya di dunia.

Hal ini tidak terlepas dari perubahan kebijakan pasar modal yang diawali sejak tahun 2002 dengan transaksi pasar modal secara online trading. Ditambah penyediaan sistem informasi fitur online trading bagi investor retail. Hal ini semakin menggairahkan transaksi pasar modal di Indonesia.

Tabel 1 World Benchmark Indices Comparison (Indonesia Stock Exchange, 2013)

\begin{tabular}{|c|c|c|c|c|c|c|c|c|c|c|c|}
\hline \multirow{2}{*}{ Country } & \multirow{2}{*}{ Index } & \multicolumn{2}{|c|}{ Daily Change } & \multirow{2}{*}{ 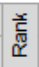 } & \multicolumn{2}{|c|}{ Month-to-Date Chg. } & \multirow{2}{*}{ 席 } & \multicolumn{2}{|c|}{ Year-to-Date Chg. } & \multirow{2}{*}{ 总 } & \multirow{2}{*}{ 30-days Chart } \\
\hline & & Points & $\%$ & & Points & $\%$ & & Points & $\%$ & & \\
\hline A Indonesia & $4,634.45$ & 32.39 & $0.70 \%$ & 5 & 180.75 & $4.06 \%$ & 3 & 317.76 & $7.36 \%$ & 5 & \\
\hline S. Korea $_{\mathrm{KOSPI}}^{\text {S. }}$ & $2,024.64$ & 38.81 & $1.95 \%$ & 1 & 62.70 & $3.20 \%$ & 4 & 27.59 & $1.38 \%$ & 10 & \\
\hline $\begin{array}{l}\text { Thailand } \\
\text { SET Index }\end{array}$ & $1,546.64$ & 14.57 & $0.95 \%$ & 2 & 72.44 & $4.91 \%$ & 1 & 154.71 & $11.11 \%$ & 1 & \\
\hline $\begin{array}{l}\text { Malaysia } \\
\text { FTSE BM }\end{array}$ & $1,613.33$ & -1.74 & $-0.11 \%$ & 12 & -14.40 & $-0.88 \%$ & 10 & -75.62 & $-4.48 \%$ & 12 & \\
\hline $\begin{array}{l}\text { Singapore } \\
\text { FTSE ST }\end{array}$ & $3,308.89$ & 13.12 & $0.40 \%$ & 7 & 28.50 & $0.87 \%$ & 8 & 141.81 & $4.48 \%$ & 8 & \\
\hline$\Delta \begin{array}{l}\text { Japan } \\
\text { Nikkei } 225\end{array}$ & $11,468.28$ & 95.94 & $0.84 \%$ & 3 & 329.62 & $2.96 \%$ & 5 & $1,073.10$ & $10.32 \%$ & 2 & \\
\hline $\begin{array}{l}\text { Hong Kong } \\
\text { Hang Seng }\end{array}$ & $23,307.41$ & 163.50 & $0.71 \%$ & 4 & -422.12 & $-1.78 \%$ & 12 & 650.49 & $2.87 \%$ & 9 & \\
\hline $\begin{array}{l}\text { China } \\
\text { SSE Comp. }\end{array}$ & $2,397.18$ & 14.27 & $0.60 \%$ & 6 & 11.76 & $0.49 \%$ & 9 & 128.05 & $5.64 \%$ & 7 & \\
\hline$\Delta_{\text {BSE Sensex }} \begin{array}{l}\text { India } \\
\text { BSE }\end{array}$ & $19,650.80$ & 1.03 & $0.01 \%$ & 11 & -278.09 & $-1.40 \%$ & 11 & 224.09 & $1.15 \%$ & 11 & \\
\hline${ }_{\text {DJAA }}^{\text {USA }^{\wedge}}$ & $14,035.67$ & 53.91 & $0.39 \%$ & 8 & 125.25 & $0.90 \%$ & 7 & 931.53 & $7.11 \%$ & 6 & \\
\hline$\Delta \begin{array}{l}\mathbf{U K}^{*} \\
\text { FTSE } 100\end{array}$ & $6,388.52$ & 9.53 & $0.15 \%$ & 10 & 111.66 & $1.78 \%$ & 6 & 490.71 & $8.32 \%$ & 4 & \\
\hline Australia & $5,114.40$ & 13.43 & $0.26 \%$ & 9 & 213.38 & $4.35 \%$ & 2 & 449.80 & $9.64 \%$ & 3 & \\
\hline
\end{tabular}

Sesungguhnya, bila pasar modal dikelola dengan lebih baik lagi, didukung dengan kebijakan dan pemanfaatan teknologi informasi secara lebih efektif, terbuka kemungkinan, pertumbuhan pasar modal Indonesia dapat bersaing dengan pasar modal Australia atau Jepang, baik dari segi jumlah pelaku pasar (investor) juga dari segi volume perdagangan.

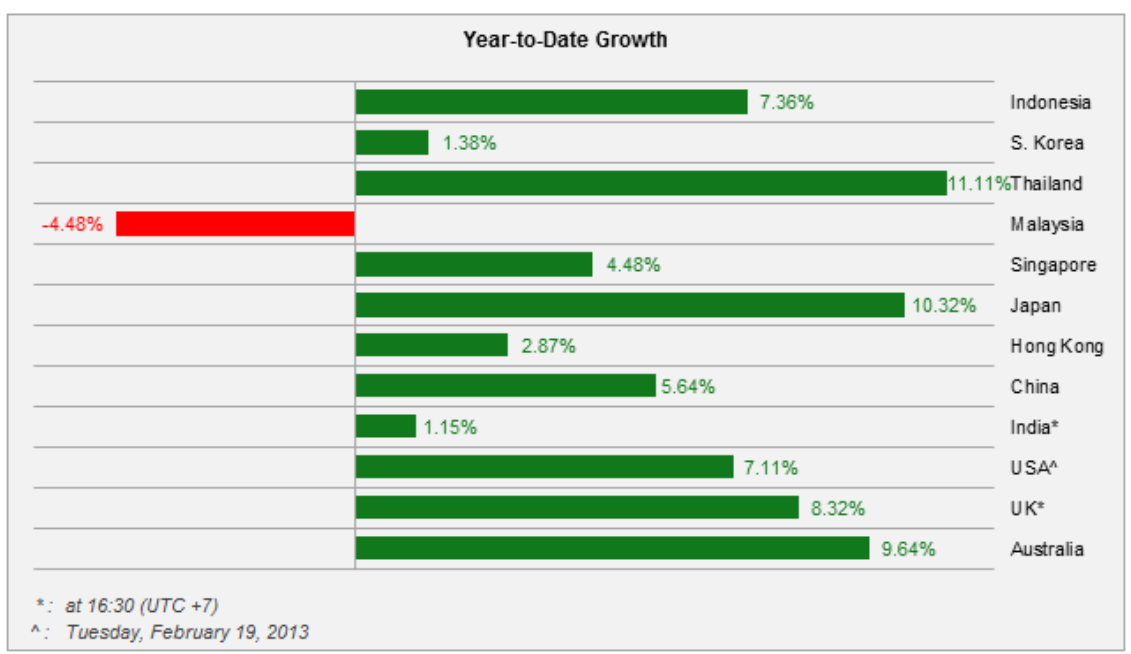

Gambar 2 Perbandingan pertumbuhan pasar modal 2012(Indonesia Stock Exchange, 2013) 
Meskipun pertumbuhan dan peningkatan pelaku pasar modal terus meningkat, faktanya, porsi pelaku asing masih cukup besar di pasar modal Indonesia. Pada Gambar 3, terlihat transaksi Jual Beli di tahun 2011: I-I sebesar 46,22\%, A-A sebesar 16,37\%, A-I sebesar 17,71\%, dan I-A sebesar 19,70\%. Sementara, ditahun 2012: I-I sebesar 36,62\% (turun 9,6\%), A-A sebesar 23,71\% (naik 7,34\%), A-I sebesar 18,13\% (naik 0,42\%), dan I-A sebesar 19,55\% (turun 0,15\%).
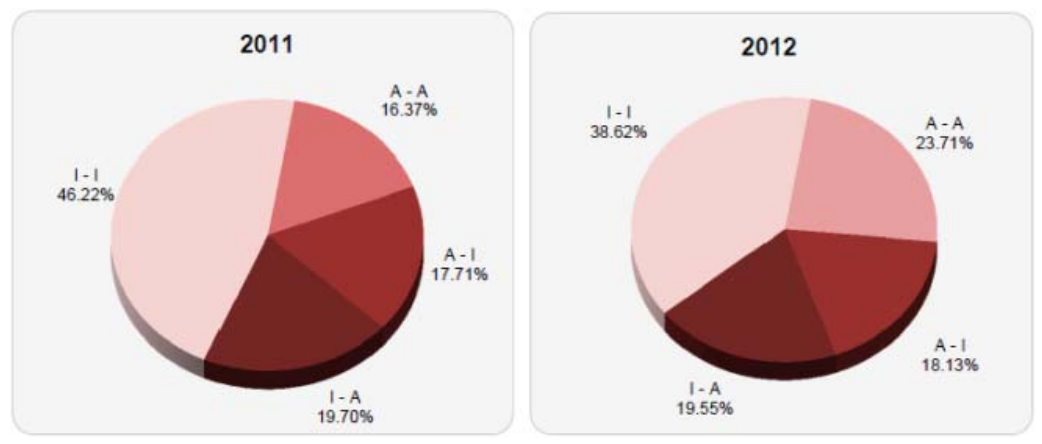

Note: $I=$ Domestic Investor, $A=$ Foreign Investors

Gambar 3 Total nilai trading value oleh investor 2011 - 2012 (Sell - Buy) (Indonesia Stock Exchange, 2013)

Dengan sinergi dari semua pihak pemangku kepentingan, sudah seharusnya pelaku pasar lokal (investor domestik) dapat menguasai transaksi pasar modal Indonesia sebesar 90\%. Dengan demikian, bila pun terjadi kondisi ekonomi global yang kurang kondusif, tidak akan mempengaruhi kinerja pasar modal Indonesia akibat kealpaan investor asing (capital inflow) atau pelarian modal (capital outflow).

Bila dilihat dari Gambar 4, transaksi trading pihak asing dipasar modal Indonesia cenderung meningkat, dari 8\% di tahun 2002 menjadi lebih dari 40\% sepanjang tahun 2012. Hal ini dapat diatasi dengan meningkatkan keterlibatan investor domestik, baik secara jumlah pelaku pasar dan juga volume transaksi.

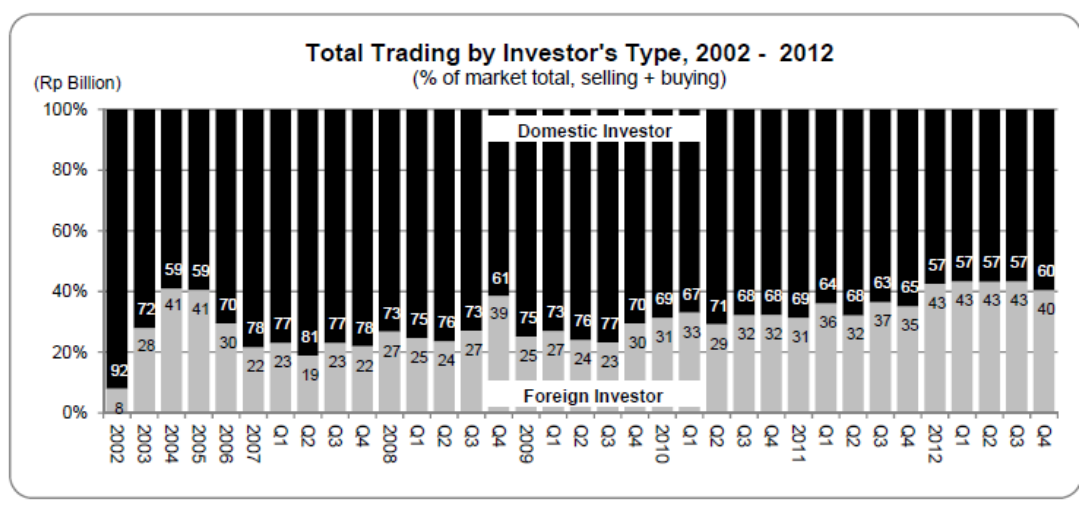

Catatan: Statistik ini dihitung berdasarkan pada jenis investor yang disediakan oleh anggota BEI pada setiap pembelian atau penjualan yang didata ke dalam sistem perdagangan BEI, bukan berdasarkan pada angka pemegang saham terdaftar yang sebenarnya dari perusahaan yang terdaftar

Gambar 4 Total trading oleh tipe investor 2002 - 2012 (Indonesia Stock Exchange, 2013)

Saat ini, diawali tahun 2006, dimana fitur online trading bagi investor ritel mulai diterapkan, semakin meningkatkan peran serta investor domestik untuk bertransaksi di pasar modal. Kemudahan 
yang dirasakan oleh pelaku pasar dengan fasilitas sistem informasi online trading memungkinkan semakin banyak masyarakat (investor) untuk mengalihkan modal uangnya di pasar modal.

Gambar 5 menunjukkan mekanisme transaksi jual beli saham secara online di pasar modal. Seorang investor, bila ingin bertransaksi dipasar modal, terlebih dahulu mendaftar lewat perusahaan efek. Kemudian mendaftarkan rekening efek di salah satu bank kustodian yang bekerja sama dengan perusahaan efek dimana sang investor terdaftar. Setelah disetujui, pihak investor menyetorkan sejumlah dana ke rekening efek, selanjutnya transaksi saham sudah dapat dilakukan.

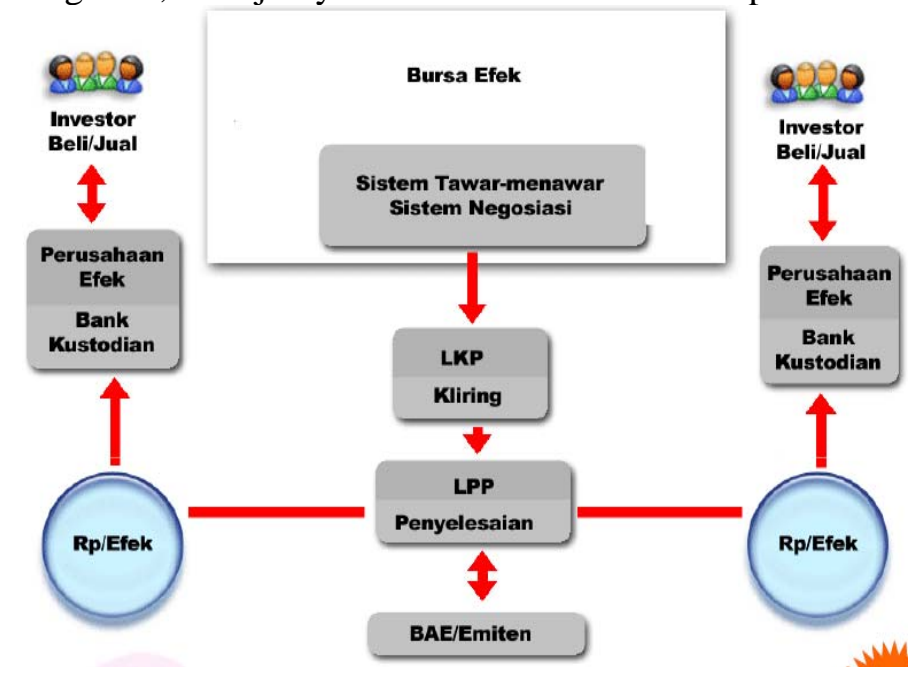

Gambar 5 Mekanisme jual beli saham secara online (Indonesia Stock Exchange, 2013)

Dengan mekanisme tersebut, cukup memudahkan bagi investor retail untuk menjadi bagian dari pasar modal Indonesia. Dengan metode online, seorang investor memiliki fleksibilitas terhadap waktu dan geografis untuk melakukan transaksi dari mana pun dan kapan pun (selama waktu buka pasar modal).

Dengan sistem online, para investor ritel dapat dengan mudah melakukan transaksi beli atau jual produk pasar modal dimana pun dan kapan pun, kemudahan memantau pergerakan harga saham selama tersedia akses Internet. Bahkan transaksi dapat dilakukan secara real time, sehingga investor dapat melakukan eksekusi transaksi saham secara cepat.

Berdasarkan data dan fakta yang telah diuraikan, sistem informasi online trading memberikan dampak yang sangat positif dan signifikan terhadap pertumbuhan dan perkembangan pasar modal Indonesia. Tren ini perlu disikapi para pelaku pasar modal untuk segera menyiapkan infrastruktur yang memadai. Selain kemudahan, yang perlu diperhatikan adalah jaminan keamanan dan kenyamanan dalam melakukan transaksi secara online. Sehingga meningkatkan kepercayaan masyarakat investor terhadap pasar modal.

Bila infrastruktur telah dipersiapkan secara baik (baik secara regulasi maupun teknis di lapangan), maka langkah selanjutnya bagaimana melakukan edukasi terhadap masyarakat agar percaya dan mau mengalihkan modal uangnya untuk bertransaksi di pasar modal.

Saat ini banyak sekali informasi terkait transaksi di pasar modal Indonesia. Dari sisi perusahaan emiten, masing-masing mereka telah menyiapkan dan menyediakan media aplikasi online, di antaranya eTrading Securities, Indo Premier Securities, Samuel Securities, BNI Securities, dan sebagian besar perbankan juga sudah memiliki fasilitas tersebut. Hal ini memudahkan bagi pelaku investor retail untuk memilih dan melakukan transaksi trading secara online. 
Hal lain terkait edukasi bagi pelaku dan calon pelaku pasar modal, perlu dilakukan forumforum yang sebagai wadah untuk bertukar informasi dan berbagi pengetahuan, tidak hanya di kotakota besar, juga ke seluruh pelosok nusantara. Agar pengetahuan akan informasi pasar modal dapat diakses oleh semua lapisan masyarakat. Dengan demikian pertumbuhan dan perkembangan pasar modal dapat lebih signifikan dalam beberapa tahun mendatang.

Di sisi lain, investor membutuhkan informasi yang rinci dan transparan sebelum mengambil keputusan investasi. Pelaku bisnis media telah menyiapkan informasi terkait pasar, di antaranya www.investasi.kontan.co.id, www.investor.co.id, dan www.pialangindonesia.com. Sementara dari sisi komunitas (baik individu maupun kelompok) banyak menyajikan analisis kondisi pasar terkini, di antaranya: www.indonesianbulls.com, www.bei5000.com, www.pembelajar.com, www.sahamonline.com, www.angguntrader.blogspot.com, dan www.finance.yahoo.com.

Dengan dukungan informasi yang detil, akan lebih memudahkan bagi pelaku pasar modal untuk menganalisis kebutuhan mereka terhadap investasi di pasar modal.

\section{PENUTUP}

Berdasarkan hasil telaah terhadap informasi terkait pertumbuhan dan perkembangan pasar modal Indonesia dapat ditarik kesimpulan, bahwa: (1) pertumbuhan pasar modal Indonesia dimulai sejak tahun 1988, namun mulai berkembang sejak dirilisnya perdagangan jarak jauh (remote trading) oleh bursa sejak tahun 2002; (2) pertumbuhan dan perkembangan pasar modal Indonesia erat terkait dengan peningkatan pemanfaatan teknologi dan sistem informasi, khususnya aplikasi online trading bagi investor retail.

Berdasarkan studi literatur ini, kajian lanjutan yang dapat dilakukan, di antaranya: (1) melakukan studi terhadap perbandingan pertumbuhan dan perkembangan pasar modal Indonesia dengan pasar modal di negara-negara ASEAN khususnya, dan Asia pada umumnya; (2) melakukan evaluasi seberapa besar tingkat kepercayaan investor retail terhadap transaksi perdagangan secara online; (3) melakukan kajian terhadap keefektifan media internet sebagai tool edukasi masyarakat terkait manfaat berinvestasi di pasar modal; (4) melakukan evaluasi terhadap fitur-fitur online trading yang telah ada, sejauh mana manfaat fitur tersebut sebagai sumber informasi bagi investor untuk mengambil keputusan investasi.

\section{DAFTAR PUSTAKA}

Bappepam Online. (2005). UU No. 8 Tahun 1995 Tentang Pasar Modal. Diakses 22 Februari 2013 dari http://www.bapepam.go.id/old/hukum/uupm/.

Bodnar, George H. dan Hopwood, William S. (2000). Sistem Informasi Akuntansi, (buku satu). Jakarta: ). Salemba Empat.

Davis, Gordon B. (1991). Kerangka Dasar Sistem Informasi Manajemen Bagian 1. Jakarta: Pustaka Binamas Pressindo.

Indonesia Stock Exchange. (2013). Bagaimana Menjadi Seorang Investor. Diakses 20 Februari 2013 dari http://www.idx.co.id/idid/beranda/informasi/bagiinvestor/bagaimanamenjadiseoranginvestor.aspx. 
Indonesia Stock Exchange. (2013). IDX Annual Report 2012. Diakses 20 Februari 2013 dari http://www.idx.co.id/id-id/beranda/ publikasi/statistik.aspx.

Lypsey R.G, Courant, P.N., Purvis, D.D. dan Steiner, P.O. (1997). Pengantar Makroekonomi. Jakarta: Bina Rupa Aksara.

Makalah tidak diterbitkan. Fakultas Hukum Universitas Diponegoro, Semarang. Diakses dari http://eprints.undip.ac.id/20437/1/2491-ki-fh-2002.pdf.

Mcleod, Raymond. (2001). Sistem Informasi Manajemen, Jakarta: Prenhallindo.

O’Brein, James A. (2005). Pengantar Sistem Informasi. Jakarta: Salemba 4.

Sriwijaya Post. (11 Juni 2012). Hanya 0,2 Persen Penduduk Indonesia yang Bermain Saham. Diakses 24 Februari 2013 dari http://palembang.tribunnews.com/2012/06/11/ hanya-02-persenpenduduk-indonesia-yang-bermain-saham.

Sutha, I.P.G.A. 2000. Menuju Pasar Modal Modern. Jakarta: Yayasan SAD Satria Bhakti.

U. Tun Wai, and Patrick, Hugh T. (1984). Stock and Bond Issues and Capital Markets in Less Developed Countries. Diakses dari http://www.palgravejournals.com/imfsp/journal/v20/n2/full/imfsp19737a.html.

Webster, E. 1999. The Economics of Intangible Investment. Cheltenham: Edward Elgar Publishing.

Widanarti, Herni. (2002). Perkembangan Pasar Modal di Indonesia: Tantangan Menyongsong Masa Depan. 